\title{
Different Types of Cerebellar GABAergic Interneurons Originate from a Common Pool of Multipotent Progenitor Cells
}

\author{
Ketty Leto, ${ }^{1 \star}$ Barbara Carletti, ${ }^{1 \star}$ Ian Martin Williams, ${ }^{1}$ Lorenzo Magrassi, ${ }^{2}$ and Ferdinando Rossi ${ }^{1}$ \\ ${ }^{1}$ Department of Neuroscience and Rita Levi Montalcini Centre for Brain Repair, University of Turin, 10125 Turin, Italy, and ${ }^{2}$ Neurosurgery, Department of \\ Surgery, Istituto di Ricovero e Cura a Carattere Scientifico Policlinico San Matteo, University of Pavia, 27100 Pavia, Italy
}

\begin{abstract}
Different cerebellar phenotypes are generated according to a precise spatiotemporal schedule, in which projection neurons precede local interneurons. Glutamatergic neurons develop from the rhombic lip, whereas GABAergic neurons originate from the ventricular neuroepithelium. Progenitors in these germinal layers are committed toward specific phenotypes already at early ontogenetic stages. GABAergic interneurons are thought to derive from a subset of ventricular zone cells, which migrate in the white matter and proliferate up to postnatal life. During this period, different interneuron categories are produced according to an inside-out sequence, from the deep nuclei to the molecular layer (we show here that nuclear interneurons are also born during late embryonic and early postnatal days, after glutamatergic and GABAergic projection neurons). To ask whether distinct interneuron phenotypes share common precursors or derive from multiple fate-restricted progenitors, we examined the behavior of embryonic and postnatal rat cerebellar cells heterotopically/ heterochronically transplanted to syngenic hosts. In all conditions, donor cells achieved a high degree of integration in the cerebellar cortex and deep nuclei and acquired GABAergic interneuron phenotypes appropriate for the host age and engraftment site. Therefore, contrary to other cerebellar types, which derive from dedicated precursors, GABAergic interneurons are produced by a common pool of progenitors, which maintain their full developmental potentialities up to late ontogenetic stages and adopt mature identities in response to local instructive cues. In this way, the numbers and types of inhibitory interneurons can be set by spatiotemporally patterned signals to match the functional requirements of developing cerebellar circuits.
\end{abstract}

Key words: cell specification; differentiation; heterotopic/heterochronic transplantation; cerebellar development; neural precursor; inhibitory interneuron

\section{Introduction}

The construction of complex neural circuits requires that different neuronal phenotypes are generated according to precise spatiotemporal schedules. This is accomplished through multiple mechanisms that instruct naive progenitor cells, restrict their developmental potentialities, or modulate their competence for adopting specific identities at defined sites and ages (Barbe and Levitt, 1991; McConnell and Kaznowski, 1991; Desai and McConnell, 2000; Livesey and Cepko, 2001; Pearson and Doe, 2004). The cellular/molecular interactions underlying cell fate

\footnotetext{
Received May 11, 2006; accepted Sept. 28, 2006.

This work was supported by grants from Ministero dell'Università e della Ricerca Scientifica e Tecnologica (Fondo per gli Investimenti della Ricerca di Base Grant RBNE01YRA3-004), Istituto Superiore di Sanità, National Program on Stem Cells (Grant CS.06), European Community (Contract 512039), Compagnia di San Paolo (Neurotransplant Project 2004.2019), Regione Piemonte (Project A14/05), and the University of Turin. B.C. is supported by a fellowship funded by Michele and Marina Petochi. I.M.W. was supported by the Marie Curie Research Training Networks on "Nervous System Repair." We thank Dr. Constantino Sotelo for his comments on this manuscript. We are indebted to Luisella Milano and Dr. Francesco Bertolo for precious technical assistance.

*K.L. and B.C. contributed equally to this work.

Correspondence should be addressed to Barbara Carletti, Rita Levi Montalcini Center for Brain Repair, Department of Neuroscience, Section of Physiology, University of Turin, Corso Raffaello 30, I-10125 Turin, Italy. E-mail: barbara.carletti@unito.it.

DOI:10.1523/JNEUROSCI.3656-06.2006

Copyright $\odot 2006$ Society for Neuroscience $\quad$ 0270-6474/06/2611682-13\$15.00/0
}

choices during neural development are still unknown, and different strategies likely operate in distinct CNS regions.

The cerebellum is most suitable to address these issues. It comprises a limited number of neuronal phenotypes, specifically integrated in the corticonuclear network and characterized by distinctive morphology and molecular markers (Ramón y Cajal, 1911; Palay and Chan-Palay, 1974). Cerebellar neurons are generated according to a well defined spatiotemporal sequence, starting from two distinct germinative neuroepithelia. Glutamatergic neurons, including deep nuclei neurons (Wang et al., 2005; Fink et al., 2006), unipolar brush cells (Englund et al., 2006), and granule cells (Alder et al., 1996; Wingate, 2001), derive from the rhombic lip (Machold and Fishell, 2005; Wang et al., 2005). GABAergic neurons, including Purkinje cells and inhibitory interneurons, originate from ptfla (pancreas transcription factor 1a)-expressing progenitors of the ventricular zone (Hoshino et al., 2005). Birthdating studies have shown that projection neurons (deep nuclei neurons and Purkinje cells) are generated first, at the onset of cerebellar neurogenesis, whereas local interneurons (either GABAergic or glutamatergic) are born during late embryonic and early postnatal life (Miale and Sidman, 1961; Altman and Bayer, 1997; Sekerková et al., 2004a,b). GABAergic interneurons derive from Pax-2 (paired box gene 2)-positive cells, 
which appear at embryonic day 13.5 (E13.5) in the ventricular zone and soon emigrate into the cerebellar parenchyma (Maricich and Herrup, 1999; Weisheit et al., 2006). These cells, which continue to proliferate after birth (Zhang and Goldman, 1996a,b), are thought to sequentially generate different types of inhibitory interneurons according to an inside-out progression (Altman and Bayer, 1997; Schilling, 2000): first in the deep nuclei, then in the granular layer (Golgi and Lugaro cells), and finally in the molecular layer (basket and stellate cells).

It is not clear whether different types of GABAergic interneurons originate from a single population of multipotent progenitors, whose fate choices are determined by site/age-specific cues or whether they derive from multiple precursor pools with restricted potentialities. Indeed, neurotransmitter phenotypes (Hoshino et al., 2005; Wang et al., 2005; Fink et al., 2006) and certain neuron identities [e.g., granule cells (Alder et al., 1996)] are specified at early stages of cerebellar ontogenesis. In addition, transplantation experiments indicate that the developmental potential of cerebellar progenitors is progressively restricted toward late-generated types (Jankovski et al., 1996; Carletti et al., 2002; Grimaldi et al., 2005). Therefore, to investigate the mechanisms that regulate the generation of GABAergic interneurons, we examined the fate of cerebellar progenitors exposed to heterotopic/ heterochronic environmental conditions. Our results indicate that GABAergic interneuron progenitors are not restricted in their developmental potential and generate different mature phenotypes appropriate for the host age and engraftment site.

\section{Materials and Methods}

Animals and surgical procedures. All experiments were performed on Wistar rats (Harlan, San Pietro al Natisone, Italy). Donor cells for transplantation experiments were obtained from transgenic rats overexpressing the enhanced green fluorescent protein (EGFP) under the control of the $\beta$-actin promoter (a generous gift from Dr. M. Okabe, Osaka University, Osaka, Japan) (Okabe et al., 1997; Ito et al., 2001). All surgical procedures were performed under deep general anesthesia obtained by intraperitoneal administration of ketamine $(100 \mathrm{mg} / \mathrm{kg}$; Ketavet; Bayer, Leverkusen, Germany) supplemented by xylazine ( $5 \mathrm{mg} / \mathrm{kg}$; Rompun; Bayer) or diazepam (2.5 mg/kg; Roche, Mannheim, Germany). The experimental plan was designed according to the European Communities Council Directive of 1986 (86/609/EEC), National Institutes of Health guidelines, and the Italian law for care and use of experimental animals (DL116/92) and was approved by the Italian Ministry of Health.

Transplantation experiments. Donor cells for heterotopic/heterochronic transplantation experiments were isolated from E14, postnatal day 1 (P1), or P7 cerebella and grafted to E15 embryos in utero and to P1, $\mathrm{P} 7$, or $\mathrm{P} 20$ hosts in vivo. The different transplantation paradigms are depicted in Figure 1. The preparation of donor cerebellar cells was performed as described previously (Jankovski et al., 1996; Carletti et al., 2002 , 2004). EGFP rat embryos were removed by cesarean section from deeply anesthetized timed-pregnant females at E14, rapidly decapitated, and dissected in saline solution with $0.6 \%$ glucose (dissection medium). To isolate postnatal cerebellar cells, P1 or P7 pups were cryoanesthetized in melting ice and rapidly transcardially perfused with $5 \mathrm{ml}$ of dissection medium to wash out blood cells. The cerebellum was removed from the skull and cut using a tissue chopper into $300-\mu \mathrm{m}$-thick parasagittal slices, collected in dissection medium. From such slices, small tissue blocks were isolated from either the apical portion of cortical folia or the periventricular region underlying the deep nuclei (Fig. $1 \mathrm{~A}$ ). Furthermore, in a specific set of experiments, the external granular layer was separated from the cortical tissue and discarded to decrease the number of granule cells in the donor cell population. Embryonic cerebellar primordia or tissue blocks from postnatal cortex or periventricular region were mechanically dissociated to a single-cell suspension. The obtained suspensions were centrifuged and resuspended at a final concentration of
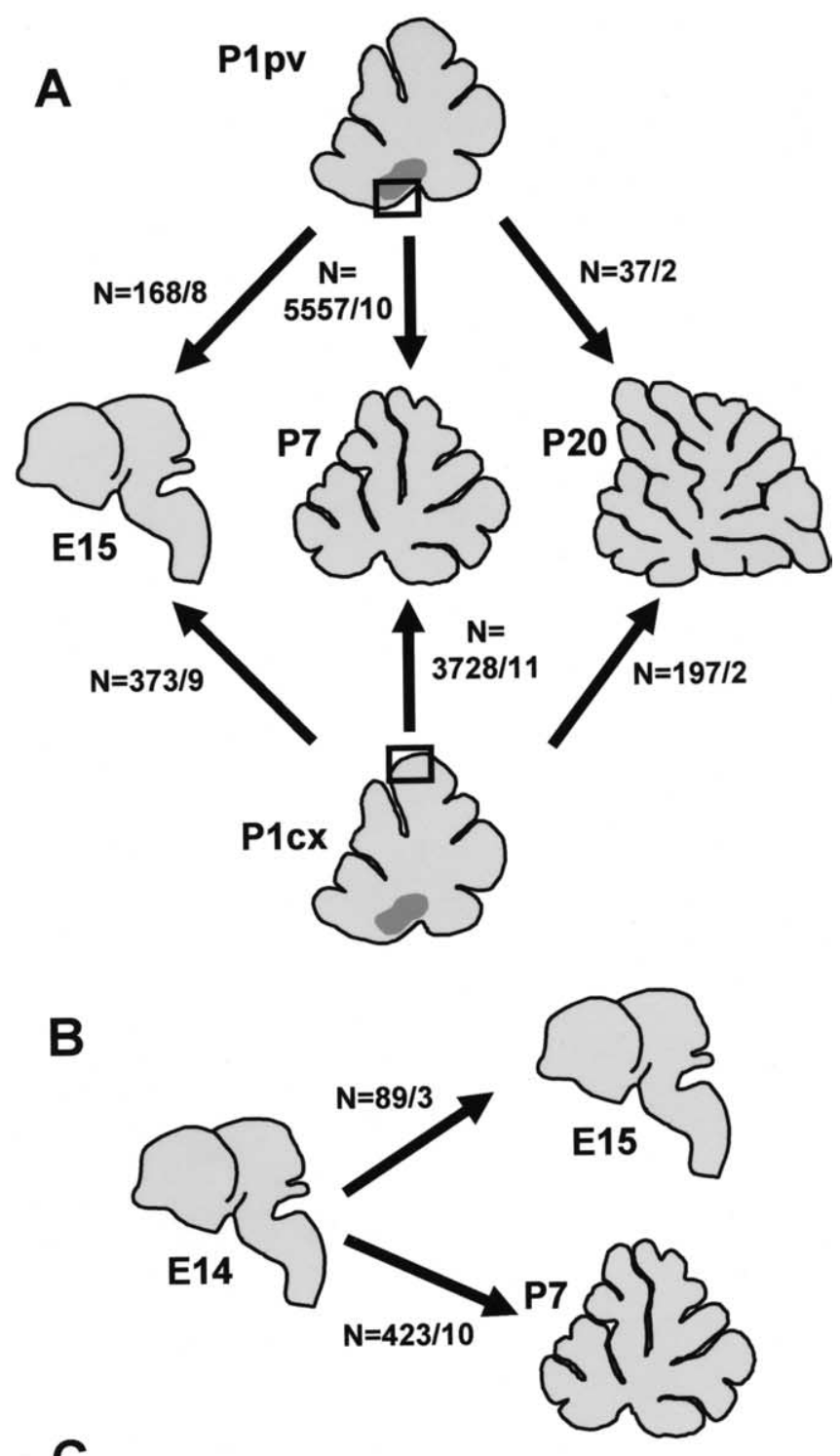

C

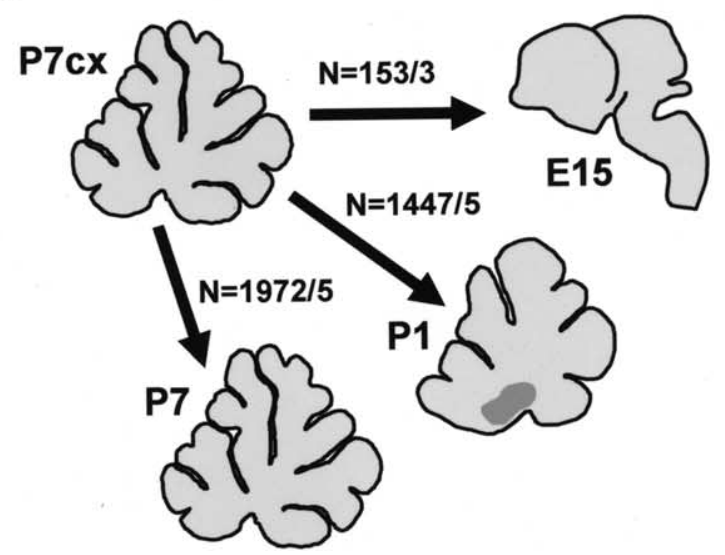

Figure 1. Schematic representation of the different transplantation paradigms applied in the study. $A$, In a first set of experiments, cerebellar cells were isolated from the periventricular region ( $P$ 1pv, boxed area) or the cortex ( $P 1 c x$, boxed area) of $P 1$ rat cerebella and grafted to $E 15$, P7, or P20 cerebella. $\boldsymbol{B}$, E14 donors were transplanted to either age-matched embryos or P7 cerebella. C, Finally, P7 cortical cells (P7cx) were grafted to E15 embryos or to P1 or P7 pups. For each condition, represented by an arrow linking donor to host, the total number of donorderived interneurons and the number of examined cases are reported. 
$5 \times 10^{4}$ cells $/ \mu$ l. An aliquot was immediately examined under the microscope to assess cell viability and EGFP expression.

Transplantation in utero. The surgical manipulation of rat embryos in utero was performed according to a previously described approach (Cattaneo et al., 1994; Carletti et al., 2002). Briefly, timed-pregnant E15 rats were deeply anesthetized, and the uterine horns were exposed. The embryonic CNS was identified under transillumination, and $2 \mu \mathrm{l}$ of the cell suspension was gently injected into the fourth ventricle by means of a glass capillary inserted through the uterine wall. The embryos were placed back into the abdomen for spontaneous delivery. Live-born recipient rats were killed at P30.

Transplantation to postnatal hosts. P1 or P7 pups were cryoanesthetized in melting ice, whereas P20 rats were deeply anesthetized as above. The posterior surface of the cerebellum was exposed by removing small fragments of the occipital bone, and $2 \mu \mathrm{l}$ of the cell suspension was injected into the parenchyma using a glass micropipette. The wound was sutured, and the animal was returned to its cage. The recipient animals were killed 3-4 weeks after transplantation, except for a group of $\mathrm{P} 7$ hosts receiving $\mathrm{P} 1$ cortical donors $(n=18)$, which were killed 1 or $2 \mathrm{~d}$ after transplantation to assess the initial placement of grafted cells.

Histological procedures. Under deep general anesthesia, recipient rats were transcardially perfused with $500 \mathrm{ml}$ of $4 \%$ paraformaldehyde in $0.12 \mathrm{M}$ phosphate buffer, $\mathrm{pH}$ 7.2-7.4. The brains were immediately dissected, stored overnight in the same fixative at $4{ }^{\circ} \mathrm{C}$, and finally transferred in $30 \%$ sucrose in $0.12 \mathrm{~m}$ phosphate buffer. The brains were cut with a cryostat in $30-\mu \mathrm{m}$-thick parasagittal slices collected in PBS. The sections were immediately examined under the microscope, and, according to the localization and morphology of transplanted interneurons, they were immunohistochemically processed to detect the expression of cell-specific antigens: calbindin (1:1500, monoclonal or polyclonal; Swant, Bellizona, Switzerland); parvalbumin (1:1500, monoclonal; Swant); anti-neurofilament SMI32 (1:250, monoclonal; Sternberger Monoclonals, Lutherville, MD); neuronal-specific nuclear protein (NeuN) (1:500, monoclonal; Chemicon, Temecula, CA); calretinin (1: 2500, polyclonal; Swant); Pax-2 (1:200, polyclonal; Zymed, San Francisco, CA); metabotropic glutamate receptor 2 (mGluR2) (polyclonal, 1:500; Chemicon); glutamic acid decarboxylase (GAD6) (1:500; monoclonal; Developmental Studies Hybridoma Bank, Department of Biological Sciences, University of Iowa, Iowa City, IA); and astrocyte-specific glutamate-aspartate transporter (GLAST) (1:4000, polyclonal; Chemicon). Some of these antibodies were also used to establish the birthdates of deep nuclei neurons and the position of Pax-2-positive cells in the postnatal cerebellum (see Results). In addition, in some cases, we also used anti-GFP antibodies (1:700, polyclonal or monoclonal; Invitrogen, Carlsbad, CA) to enhance the intrinsic fluorescence of transplanted cells.

Incubation of cerebellar slices with primary antibodies was made overnight at room temperature in PBS with $1.5 \%$ normal serum and $0.25 \%$ Triton X-100. The sections were then exposed for $1 \mathrm{~h}$ at room temperature to secondary biotinylated antibodies followed by a solution of streptavidin Texas Red conjugate (1:200; Invitrogen) or fluoresceinated second antibody (1:200; Vector Laboratories, Burlingame, CA). In some cases, we also used propidium iodide (Sigma, St. Louis, MO) or $4^{\prime}, 6-$ diamidino-2-phenylindole (DAPI) (Fluka, Buchs, Switzerland) to counterstain cell nuclei. The stained sections were mounted on microscope slides with Tris-glycerol supplemented with $10 \%$ Mowiol (Calbiochem, La Jolla, CA) to reduce fading of fluorescence.

Bromodeoxyuridine labeling. To assess the birthdates of interneurons in the deep nuclei, bromodeoxyuridine (BrdU) (50 $\mu \mathrm{g} / \mathrm{g}$ body weight, dissolved at $5 \mathrm{mg} / \mathrm{ml}$ in $0.007 \mathrm{~N} \mathrm{NaOH}$ in normal saline) was intraperitoneally injected to the pregnant dams or to the rat pups (two injections each day during different time windows, as shown in Fig. 2). The treated animals were killed at 1 month of age. In addition, to determine the position of proliferating cells in the postnatal cerebellum, two injections of $\mathrm{BrdU}$ (within a $3 \mathrm{~h}$ period) were made to $\mathrm{P} 1$ pups that were killed $2 \mathrm{~h}$ after the last administration. In all instances, the brains were fixed and cryostat sectioned as above; sections were incubated in $2 \mathrm{~N} \mathrm{HCl}$ for 20 min at $37^{\circ} \mathrm{C}$, exposed to anti-BrdU antibodies (1:500, monoclonal; Sigma) overnight at $4^{\circ} \mathrm{C}$, and then reacted with fluoresceinated second antibody.

Retrograde tracing of the nucleo-olivary pathway. To establish the birthdate of nucleo-olivary projection neurons, $\mathrm{BrdU}$ (as above) was injected to rat embryos at E13-E15 $(n=3)$ or E19-E21 $(n=2)$. At 2 months of postnatal age, the axonal tracer Fluoro Ruby (tetra-methyl-rhodamineconjugated dextran, 10,000 molecular weight; Invitrogen) was injected into the inferior olive according to a well established approach (Rossi et al., 1991). Briefly, glass micropipettes (inner tip diameter of $30 \mu \mathrm{m}$ ) were placed $0.5-0.8 \mathrm{~mm}$ deep in the medulla oblongata and $1 \mu \mathrm{l}$ of Fluoro Ruby ( $10 \%$ solution in $0.12 \mathrm{~m}$ phosphate buffer, $\mathrm{pH} 7.2$ ) was pressure injected in 10-15 min by means of a PV800 pneumatic picopump (World Precision Instruments, New Haven, CT). The animals were killed $10 \mathrm{~d}$ after tracer application.

Data analysis. The histological preparations were examined by means of a Zeiss (Oberkochen, Germany) Axiophot light microscope, equipped with a Nikon (Melville, NY) DS-5M digital camera. The material was also examined with an Olympus Optical (Hamburg, Germany) Fluoview 300 confocal microscope. Digital images were processed with Adobe Photoshop 6.0 (Adobe Systems, San Jose, CA) to adjust contrast and assemble the final plates. Quantitative and morphometric evaluations were made using the Neurolucida software (MicroBrightField, Colchester, VT) connected to an E-800 Nikon microscope via a color CCD camera.

Different types of deep nuclei neurons were classified according to the expression of three main markers: NeuN, SMI32, and calretinin. In 
Table 1. Distribution of interneuron phenotypes generated by P1 donor cells transplanted to P7 cerebella, according to their placement in the host cortex or in the cortex and in the deep cerebellar parenchyma

\begin{tabular}{|c|c|c|c|c|c|c|c|c|c|c|c|}
\hline \multicolumn{6}{|c|}{ cx donors $>$ cortex } & \multicolumn{6}{|c|}{ cx donors $>$ cortex/deep cerebellum } \\
\hline case & $\mathrm{ml}$ & $\mathrm{gl}$ & $d n$ & wm & tot & case & $\mathrm{ml}$ & $\mathrm{gl}$ & $\mathrm{dn}$ & wm & Tot \\
\hline $9 c$ & 14 & 0 & 0 & 0 & 14 & $7 c$ & 62 & 0 & 0 & 0 & 62 \\
\hline $10 c$ & 525 & 1 & 0 & 0 & 526 & $2 c$ & 492 & 3 & 0 & 0 & 495 \\
\hline $11 c$ & 299 & 0 & 0 & 1 & 300 & $3 c$ & 513 & 0 & 0 & 0 & 513 \\
\hline 1c & 279 & 0 & 0 & 0 & 279 & $6 c$ & 417 & 0 & 0 & 0 & 417 \\
\hline $4 c$ & 439 & 0 & 0 & 0 & 439 & & & & & & \\
\hline $5 c$ & 101 & 0 & 0 & 0 & 101 & & & & & & \\
\hline $8 c$ & 582 & 0 & 0 & 0 & 582 & & & & & & \\
\hline tot & 2239 & 1 & 0 & 1 & 2241 & tot & 1484 & 3 & 0 & 0 & 1487 \\
\hline
\end{tabular}

\begin{tabular}{|c|c|c|c|c|c|c|c|c|c|c|c|}
\hline \multicolumn{6}{|c|}{ pv donors $>$ cortex } & \multicolumn{6}{|c|}{ pv donors $>$ cortex/deep cerebellum } \\
\hline case & $\mathrm{ml}$ & $\mathrm{gl}$ & $\mathrm{dn}$ & wm & tot & case & $\mathrm{ml}$ & gl & $\mathrm{dn}$ & wm & Tot \\
\hline $1 p$ & 115 & 0 & 0 & 0 & 115 & $2 p$ & 783 & 4 & 2 & 0 & 789 \\
\hline $4 p$ & 129 & 2 & 0 & 0 & 131 & $3 p$ & 375 & 4 & 0 & 0 & 379 \\
\hline $8 p$ & 50 & 0 & 0 & 0 & 50 & $5 p$ & 107 & 1 & 0 & 0 & 108 \\
\hline $9 p$ & 770 & 3 & 0 & 0 & 773 & $6 p$ & 3108 & 24 & 1 & 0 & 3133 \\
\hline $10 p$ & 21 & 0 & 0 & 0 & 21 & $7 p$ & 56 & 0 & 2 & 0 & 58 \\
\hline tot & 1085 & 5 & 0 & 0 & 1090 & tot & 4429 & 33 & 5 & 0 & 4467 \\
\hline
\end{tabular}

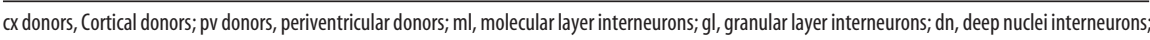
wm, ectopic interneurons in white matter.

Table 2. Distribution of phenotypes generated by P1 cortical donor cells (top) or cortical donor cells without external granular layer (bottom) transplanted to P7 cerebella

\begin{tabular}{lcccc}
\hline Cortical cells & & & & \\
\hline Case & Sample size & Granule cells & Interneurons & Glia \\
\hline $10 c$ & 1271 & $1238(97.4 \%)$ & $23(1.8 \%)$ & $10(0.8 \%)$ \\
$9 c$ & 636 & $557(87.6 \%)$ & $15(2.3 \%)$ & $64(10.1 \%)$ \\
$8 c$ & 1324 & $1111(83.9 \%)$ & $87(6.6 \%)$ & $126(9.5 \%)$ \\
$11 c$ & 1093 & $910(83.2 \%)$ & $103(9.5 \%)$ & $80(7.3 \%)$ \\
3 & 1005 & $809(80.5 \%)$ & $174(17.3 \%)$ & $22(2,2 \%)$ \\
6 & 1069 & $855(80 \%)$ & $24(2.2 \%)$ & $190(17.8 \%)$ \\
5 & 424 & $338(79.7 \%)$ & $82(19.4 \%)$ & $4(0.9 \%)$ \\
7 & 827 & $628(75.9 \%)$ & $42(5.1 \%)$ & $157(19 \%)$ \\
2 & 1868 & $1162(62.2 \%)$ & $183(9.8 \%)$ & $523(28 \%)$ \\
1 & 2377 & $1377(57.9 \%)$ & $214(9 \%)$ & $786(33.1 \%)$ \\
4 & 1347 & $567(42.1 \%)$ & $272(20.2 \%)$ & $508(37.7 \%)$ \\
Cortical cells without egl & & & $84(44.2 \%)$ \\
\hline Case & Sample size & Granule cells & & $1683(64.5 \%)$ \\
\hline 1e & 190 & $75(39.5 \%)$ & Interneurons & $159(61.2 \%)$ \\
4 4e & 2611 & $740(28.3 \%)$ & $31(16.3 \%)$ & $51(28.9 \%)$ \\
2e & 260 & $71(27.3 \%)$ & $188(7.2 \%)$ & Glia \\
3e & 205 & $40(19.5 \%)$ & $114(55.6 \%)$ & \\
\hline
\end{tabular}

Data from single cases are ordered according to the relative frequency of granule cells. egl, External granular layer. size), and (4) position in the host cortical layers or deep nuclei. The different types of GABAergic interneurons were identified according to the expression pattern of a set of distinctive markers and assigned to different categories: deep nuclei interneurons [NeuN/calretinin (Bastianelli, 2003; Weyer and Schilling, 2003)]; granular layer interneurons for Golgi [mGluR2/Pax-2 (Weyer and Schilling, 2003; Grimaldi and Rossi, 2006)] and Lugaro cells [calretinin (Dino et al., 1999; Bastianelli, 2003)]; and molecular layer interneurons for basket and stellate cells [parvalbumin (Celio, 1990)]. Except for rare elements ectopically positioned in the white matter (see below and Fig. 8 ), the distinctive features of donor-derived GABAergic interneurons (i.e., morphology, marker expression, and position) were always congruent and consistent, so that their identity could be unequivocally established. By means of the Neurolucida system, the position of EGFP-positive GABAergic interneurons was recorded and their number was evaluated. Given the variable amounts of donor cells that engrafted in different cases, results obtained from different grafts belonging to the same experimental set were pooled together. The number of GABAergic interneurons and the number of examined cases for each experimental set are indicated in Figure 1. The relative frequencies of interneuron types in the deep nuclei, granular and molecular layers, are reported in Figure 8 . In addition, the distribution of interneuron phenotypes observed in transplants of $\mathrm{P} 1 \mathrm{do}-$ nors to P7 hosts is illustrated in Table 1, in which data from single cases are reported according to the graft placement in the recipient cortex or in the cortex and in the deep cerebellum. Finally, to assess whether the phenotypic distribution of donor-derived interneurons is influenced by the composition of the donor cell populations, we examined grafts of P1 cortical cells (with or without the external granular layer) transplanted to P7 cerebella (Table 2). All of the EGFP-positive cells present in 10 randomly selected sections from each case were counted and assigned to different categories: granule cells, inhibitory interneurons, and glia (the rare unipolar brush cells were not included). addition, nucleo-olivary projection neurons were identified through retrograde axonal tracing from the inferior olive. The cell body size of nuclear neurons was measured with the Neurolucida system at $40 \times$ magnification, on a sample of 10,444 cells from 10 animals (Fig. 2 A). To determine the birthdates of the different subpopulations of deep nuclei neurons, we counted the numbers of cells double labeled for BrdU and one of the above markers on a sample of 7677 cells from 17 animals (Fig. $2 B, C)$.

To evaluate the distribution of proliferating Pax-2-positive interneuron progenitors, $\mathrm{P} 1$ rats were killed $2 \mathrm{~h}$ after pulse injections of BrdU, and cerebellar sections were processed for Pax-2 and BrdU immunocytochemistry (see above). The number of Pax-2-positive cells and the relative fraction of $\mathrm{Pax}-2 / \mathrm{BrdU}$ double-labeled nuclei in the periventricular region, deep nuclei, cortical white matter, and cortical layers were counted on several confocal images.

Transplanted cells in the host tissue were recognized by the strong intrinsic fluorescence. Their phenotypes were determined on the basis of several criteria, including (1) morphological features, (2) expression of type-specific markers, (3) morphometric parameters (e.g., cell body

\section{Results}

To assess whether cerebellar GABAergic interneurons derive from a common progenitor pool or from distinct subsets of faterestricted precursors, we used a heterotopic/heterochronic transplantation approach. Because the different types of GABAergic interneurons are generated according to a precise spatiotemporal sequence, we asked whether donor cells displaced in space or time retained their original fate or acquired new identities according to the host age and/or engraftment site.

Although there is general agreement about the generation schedule of cortical interneurons (Miale and Sidman, 1961; Altman and Bayer, 1997; Sekerková et al., 2004a,b), some inconsistencies exist about the birth of deep nuclei interneurons. Although birthdating studies indicate that all nuclear neurons are generated at the beginning of cerebellar neurogenesis [i.e., between E13 and E15 in the rat (Altman and Bayer, 1978, 1997; Sekerková et al., 2004a)], other reports suggest that local inter- 
neurons have a different origin than projection neurons (Hoshino et al., 2005; Wang et al., 2005; Fink et al., 2006) and may be also generated at later stages (Maricich and Herrup, 1999). Therefore, as a preliminary step for our study, we reexamined deep nuclei neurogenesis to define the time window in which local interneurons are born.

\section{Birthdates of deep nuclei neurons}

The cerebellar nuclei comprise three main neuron categories that differ in size, neurotransmitter, and connectivity (Chan-Palay, 1977; Batini et al., 1992; De Zeeuw and Berrebi, 1995; Sultan et al., 2003): (1) large nucleofugal glutamatergic neurons that project to different extracerebellar sites, (2) medium-sized GABAergic nucleo-olivary projection neurons, and (3) small local GABAergic interneurons. Among the markers applied to distinguish between these types in adult rats, we found that NeuN labels the nucleus and perikaryal cytoplasm of virtually all nuclear neurons (Figs. 2A, 3C,D) (Mullen et al., 1992; Weyer and Schilling, 2003). In contrast, SMI32 and calretinin identify two primarily nonoverlapping neuronal subsets (of a sample of 1310 neurons, only 27 were double labeled): the former marker decorates large polygonal neurons (Figs. 2A, 3A,B) (Jankovski et al., 1996), whereas the latter stains smaller ovoid-shaped cells (Figs. $2 A$, $3 E, F)$ (Bastianelli, 2003). Hoshino et al. (2005) reported that the SMI32-positive cells do not colabel with anti-GABA antibodies and represent the large glutamatergic projection neurons. In our material, calretinin-immunoreactive cell bodies and terminals in the deep cerebellar nuclei were consistently colabeled with antiGAD6 antibodies. As a consequence, the smaller calretininimmunopositive cells encompass GABAergic neurons of the deep nuclei.

To establish the birthdates of the different types of nuclear neurons, we examined BrdU immunoreactivity after administration of this nucleotide analog during different time windows, spanning embryonic and postnatal life (Figs. 2B, $C, 3 A-I$ ). SMI32-positive neurons are exclusively labeled when the injections are made between E13 and E15. In contrast, calretininimmunostained cells incorporate BrdU during the whole fetal life and the first postnatal week, although the number of labeled cells progressively decreases. Analysis of cell size distributions confirms that all of the large NeuN/SMI32-positive neurons are born before E15, whereas the generation of smaller NeuN/calretininpositive cells continues at later stages (Fig. 2C).

GABAergic neurons in the deep nuclei comprise both local interneurons and nucleo-olivary projection neurons (Nelson and Mugnaini, 1989; Ruigrok, 1997). To establish when the latter neurons are generated, we injected the retrograde axonal tracer Fluoro Ruby in the inferior olive of adult rats who received BrdU injections at E13-E15 or E19-E21. In the former set, $88.2 \%$ of traced neurons were also stained by anti-BrdU antibodies ( 523 of 593 cells) (Fig. 3J), whereas no double-labeled cells were found in the latter ( $n=243$ cells). In addition, the vast majority of Fluoro Ruby-traced neurons were also SMI32 positive ( 652 of 692 cells) (Fig. $3 K$ ), but very few of them were stained by calretinin ( 2 of 732 cells) (Fig. $3 L, M$ ). Therefore, nucleo-olivary GABAergic projection neurons are generated between E13 and E15 and belong to the category of large SMI32-positive neurons. Together, these observations show that, in the cerebellar nuclei, all projection neurons, either glutamatergic or GABAergic, are born between E13 and E15, whereas local GABAergic interneurons, which can be identified by their smaller size and calretinin immunostaining, are generated over a longer time window extended to early postnatal days.
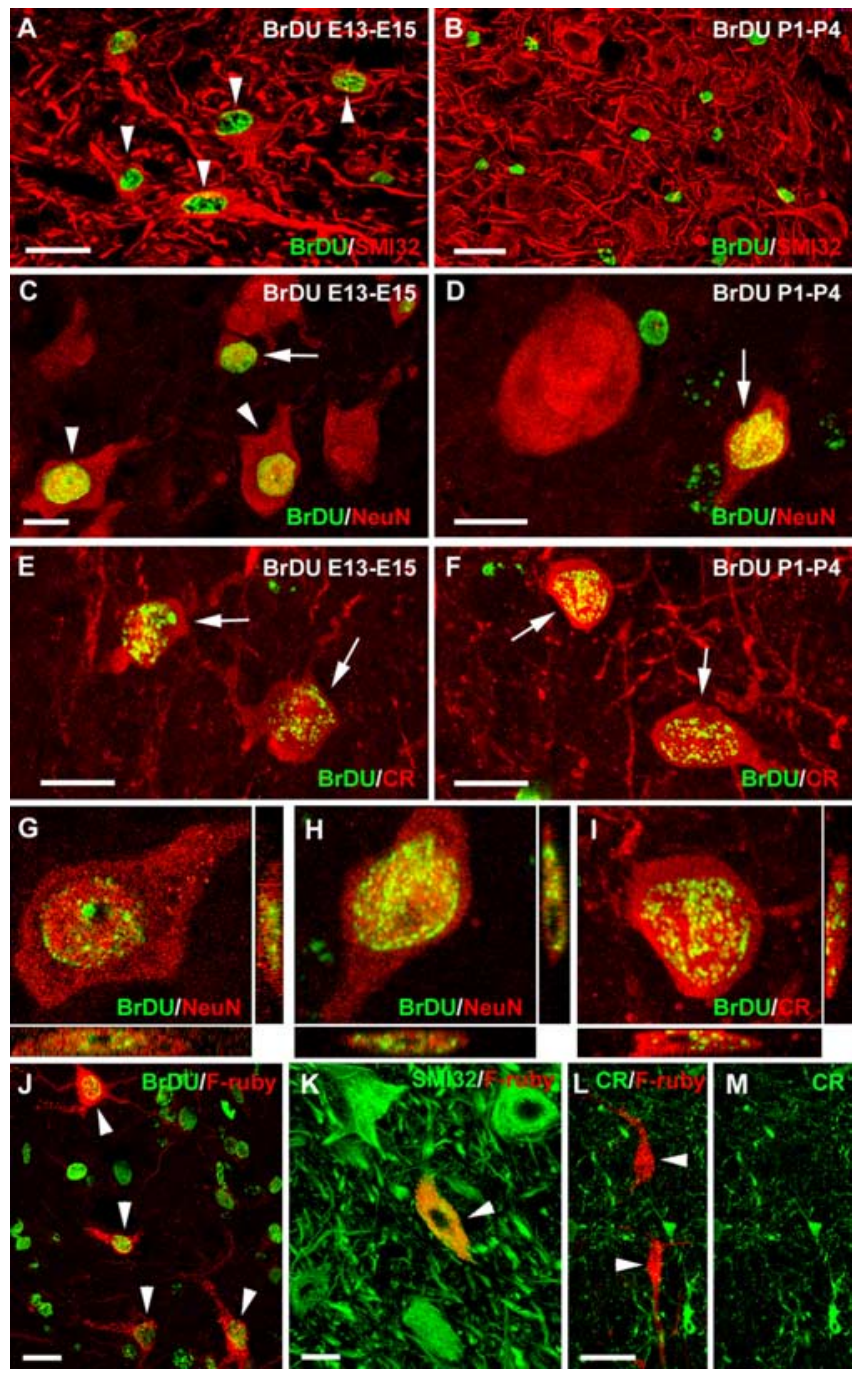

Figure 3. $A-M$, Birthdating of deep nuclei neuron subtypes. $A-F$, Immunolabeling of deep nuclei neurons after administration of BrdU at E13-E15 $(\boldsymbol{A}, \boldsymbol{C}, \boldsymbol{E})$ or P1-P4 $(\boldsymbol{B}, \boldsymbol{D}, \boldsymbol{F})$. Double immunostaining for BrdU (green) and SMI32 (red, $A, B), \operatorname{NeuN}($ red, $C, D)$, or calretinin (CR, red, $\boldsymbol{E}, \boldsymbol{F}$ ). Large SMI32/NeuN-immunoreactive neurons with BrdU-positive nuclei (pointed by arrowheads in $A, C$ are exclusively present after BrdU application at E13-E15. In contrast, small NeuN/calretinin-immunolabeled cells incorporate BrdU at both ages (arrows in $\mathbf{C}-\boldsymbol{F}$ ). $\mathbf{G}-\boldsymbol{I}$, Multiplane views demonstrate the nuclear labeling of some of the neurons depicted in the above micrographs. Nucleo-olivary projection neurons, stained in red by retrograde Fluoro Ruby (F-ruby) tracing from the inferior olive, are indicated by arrowheads in $\mathrm{J}$ : these neurons incorporated BrdU (green) administered between E13 and E15. $\boldsymbol{K}$ and $\boldsymbol{L}, \boldsymbol{M}$ show that the Fluoro Ruby-traced nucleo-olivary neurons (red, arrowheads in $K, \boldsymbol{L}$ ) are double labeled for SMI32 (green in $\boldsymbol{K}$ ) but not for calretinin (green in $L, M$ ). Scale bars: $A, B, J, L, 20 \mu \mathrm{m} ;(-F, K, 10 \mu \mathrm{m}$.

\section{Localization of interneuron progenitors in the postnatal cerebellum}

Together with previous birthdating studies (Altman and Bayer, 1997; Sekerková et al., 2004a; Yamanaka et al., 2004), our present analyses indicate that cerebellar GABAergic interneurons are generated between E13 and P15. Within this time window, the different phenotypes are produced during overlapping periods, according to an inside-out sequence: first in the deep nuclei, then in the granular layer, and, finally, in the molecular layer. To investigate the mechanisms that regulate this generation sequence, we first considered P1 cerebella, when nuclear and granular layer interneurons are still produced and the first molecular layer interneurons are being generated (Altman and Bayer, 1997; Sekerková et al., 2004a; this study). At this age, presumptive Pax- 

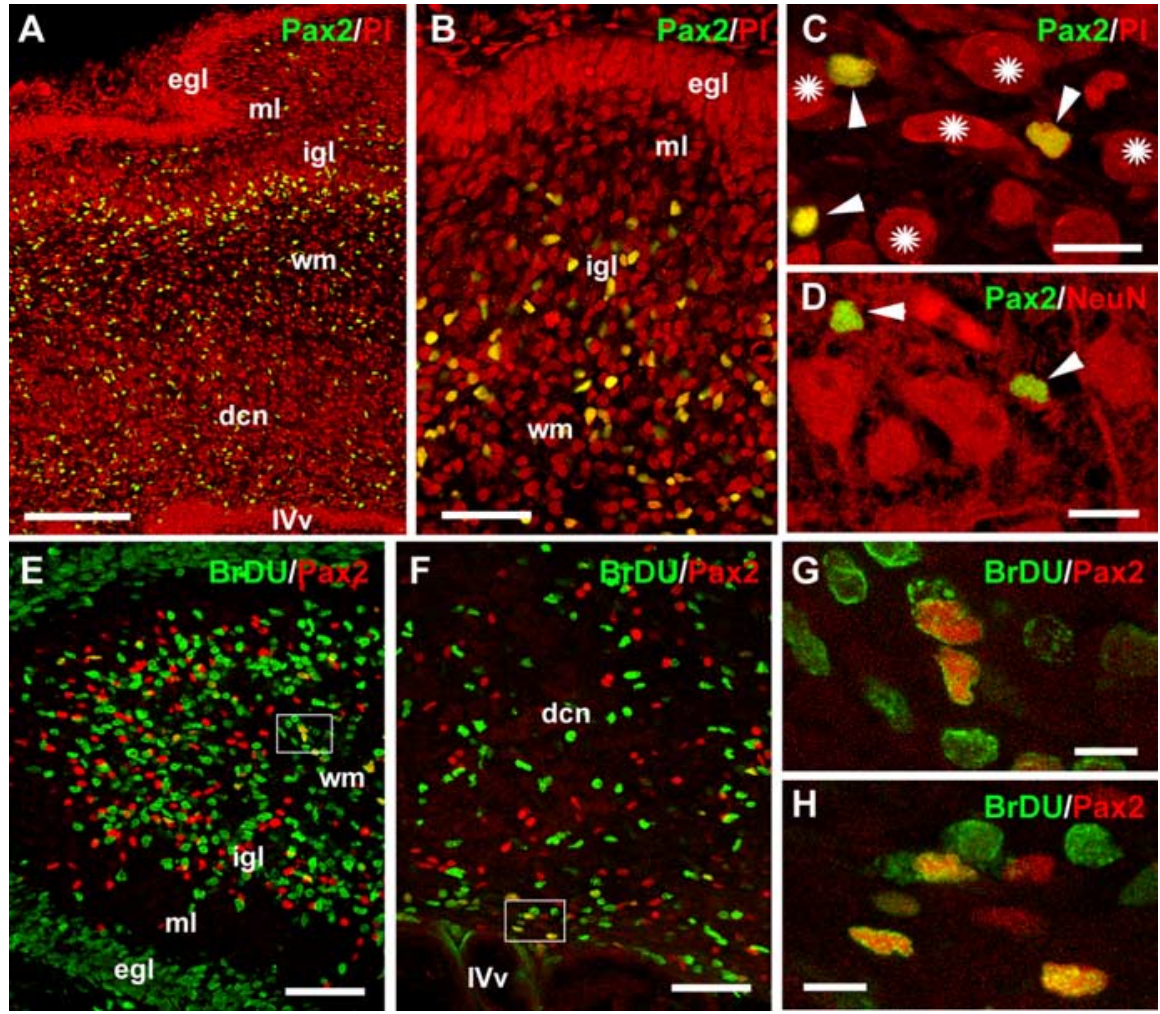

Figure 4. $\mathbf{A}-\boldsymbol{H}$, Distribution and proliferation of Pax-2-expressing cells in P1 cerebellum. At this age, Pax-2-positive cells, which appear yellow in $\boldsymbol{A}-\mathbf{C}$ because of double labeling with propidium iodide (PI, red), are present in both the cortex and the region of the nuclei $(\mathrm{dcn})$, being more numerous at the border between the white matter (wm) and the nascent internal granular layer (igl). The distribution of these cells in the cortex can be also appreciated by the higher-magnification picture $\boldsymbol{B}$. Arrowheads in $\mathbf{C}$ point to small Pax-2-expressing cells intermingled with large deep nuclei neurons (some are indicated by asterisks). Some of such cells are also double labeled with anti-NeuN antibodies (arrowheads in D). $\boldsymbol{E}-\boldsymbol{H}$ show double labeling for BrdU (green) and Pax-2 (red) in the cortex $(\boldsymbol{E}, \boldsymbol{G})$ or periventricular region $(\boldsymbol{F}, \boldsymbol{H})$ after a pulse of BrdU. Note that double-labeled cells are most frequent in the cortical white matter $(\mathrm{wm}, \boldsymbol{E})$ and in the region bordering the fourth ventricle $(\mathrm{IVv}, \boldsymbol{F})$. The higher-magnification pictures $\boldsymbol{G}$ and $\boldsymbol{H}$ show the double-labeled nuclei contained in the insets in $\boldsymbol{E}$ and $\boldsymbol{F}$, respectively. egl, External granular layer, $\mathrm{ml}$ molecular layer; igl, internal granular layer; $w m$, white matter; $d c n$, deep cerebellar nuclei; IVv, fourth ventricle. Scale bars: $A, 200$ $\mu \mathrm{m} ; \boldsymbol{B}, \boldsymbol{E}, \boldsymbol{F}, 100 \mu \mathrm{m} ; \boldsymbol{C}, \boldsymbol{D}, 20 \mu \mathrm{m} ; \boldsymbol{G}, \boldsymbol{H}, 10 \mu \mathrm{m}$.

2-positive GABAergic interneuron precursors are distributed throughout the cerebellar parenchyma (Fig. 4A) (Maricich and Herrup, 1999; Weisheit et al., 2006). In the cortex, they are most frequent at the border between the white matter and the internal granular layer (Fig. 4A,B). In addition, Pax-2-positive cells are present close to the ventricular surface and in the deep nuclei, in which some colabel with NeuN (Fig. 4A, C,D). After pulse injections of BrdU, numerous proliferating cells can be seen throughout the cerebellar parenchyma, including all cortical layers (Fig. $4 E$ ) and the region of the deep nuclei (Fig. 4F). Pax-2-positive cells double labeled for BrdU are more frequent along the axial white matter of cortical folia (Fig. $4 E, G$ ) [Pax-2/BrdU doublelabeled cells, $34.5 \%$ in lobule white matter $(n=238)$ and $7.8 \%$ in cortical layers $(n=357)]$ and in the vicinity of the ventricular surface (Fig. 4F,H) [Pax-2/BrdU double-labeled cells, 35.2\% in periventricular region $(n=91)$ and $5.3 \%$ in deep nuclei $(n=$ $284)$ ]. These observations indicate that proliferating progenitors for GABAergic interneurons are particularly enriched in these sites and suggest that distinct progenitor pools, with specific properties and competences, may be spatially segregated in different positions. Thus, we asked whether progenitor cells residing in the cortical lobules or in the periventricular region share the same developmental potentialities. However, because it is not definitely established whether Pax-2 is expressed by all GABAer- gic interneuron progenitors (Maricich and Herrup, 1999; Koscheck et al., 2003) and it is not present in other lineages (Kioussi and Gruss, 1994), we transplanted the entire population of cerebellar cells dissected from either site.

\section{GABAergic interneuron progenitors isolated from the} cortex or the periventricular region have similar developmental potentialities

Cortical or periventricular cells from P1 cerebella were heterochronically transplanted to E15 embryos, at the onset of interneuron production, or to $\mathrm{P} 7$ pups, toward the end of the generation period. In all instances, the phenotypic repertoires generated by donor cells were examined several weeks later, after the completion of cerebellar development. In line with our previous observations (Carletti et al., 2002), in both recipients, P1 donors acquired different neuronal and glial identities (Table 2) but did not generate Purkinje cells or large/SMI32-positive deep nuclear neurons. The main difference between grafts of cortical and periventricular donors was that granule cells were abundant in the former but absent in the latter. When present, granule neurons were either morphologically integrated in the recipient granular layer or, less frequently, gathered in dense aggregates in the deep white matter or along the cerebellar peduncles (Fig. 5 H,I) (Carletti et al., 2002).

Excluding granule neurons, the relatively small amount of donor cells of either origin injected into each embryonic brain yielded several tens of EGFP-positive interneurons (Fig. 1A), distributed in different sites of the recipient cerebellum. In the deep nuclei, donor-derived nerve cells displayed small ovoid-shaped perikarya covered by Purkinje axon terminals, long slender dendrites, and short axons that soon broke in terminal arbors (Fig. $5 A-D$ ). In the granular layer, EGFP-positive neurons displayed the typical morphology and localization of Golgi (Fig. 5E,F) and Lugaro cells (Fig. 5G), whereas in the molecular layer they showed distinctive features and connectivity of basket and stellate cells (data not shown). In all instances, EGFP-positive cells colabeled with type-specific markers consistent with their morphology and location, such as calretinin and NeuN in the deep nuclei (Fig. 5C,D), Pax-2 and mGluR2 for granular layer interneurons (Fig. 5E), and parvalbumin for molecular layer interneurons (data not shown). In contrast, there were no cases in which donor-derived cells stained positive for a marker inappropriate for their position or morphological phenotype. Therefore, with the exception of rare neurons displaced in the white matter, both cortical and periventricular cells generated fully differentiated and anatomically integrated GABAergic interneurons. The amount and frequency of different phenotypes was fairly similar for both donors (see Fig. $8 \mathrm{~A}$ ): interneurons of the granular layer were most numerous, followed by those of deep nuclei and molecular layer, which were the least represented types. Finally, another interesting feature observed in 
the grafts of cortical cells was the presence of parvalbumin-immunopositive interneurons of host origin (i.e., EGFPnegative cells) in the vicinity of the clusters of donor granule cells ectopically positioned in the deep white matter or cerebellar peduncles (Fig. $5 H, I$ ). This observation suggests that signals issued by misplaced granule cells are sufficient to induce the differentiation of nearby host progenitors into molecular layer interneurons.

When P1 cells were grafted to P7 hosts, the number of donor-derived interneurons (Fig. $1 A$ ) and the frequency of the different phenotypes (see Fig. $8 B$ ) were remarkably different from those observed in embryonic hosts. In both cortical and periventricular grafts, the most abundant type of interneuron was now represented by several hundreds of parvalbuminimmunopositive basket and stellate cells (Fig. 5M-Q), the latter being more numerous $(68.2 \%)$. In contrast, other types were extremely rare (see Fig. $8 \mathrm{~B}$ ). These grafts also produced some unipolar brush cells (Fig. 5J-L), a category of glutamatergic interneurons that were rarely encountered when the same donors were transplanted to embryonic cerebella.

These observations indicate that the fate of donor cells of either origin was primarily influenced by the ongoing neurogenic processes in the host tissue. Therefore, we made additional transplantation experiments to 20 -d-old recipients, toward the end of cerebellar neurogenesis (Altman and Bayer, 1997). Again, both cortical and periventricular donors yielded the same phenotypes (see Fig. 8C), almost exclusively represented by molecular layer interneurons, including $>95 \%$ stellate cells located in the outermost portion of the molecular layer (Fig. 5R). Sparse unipolar brush cells were also present in these transplants.

The repertoire of interneurons generated by $\mathrm{P} 1$ progenitors in postnatal cerebella could be influenced by the initial placement of the grafted cells. During postnatal development, the cerebellar cortex is greatly expanding, and, hence, basket and stellate cells may be more frequently generated because donor cells are preferentially exposed to the molecular layer environment. To elucidate this point, we made two distinct analyses. First, we examined the position of donor cells in animals killed 1 or $2 \mathrm{~d}$ after transplantation made at P7. In all cases, EGFP-positive cells were present in the host cortex. They were usually dispersed along the axial white matter of a lobule (Fig. $6 B$ ), from
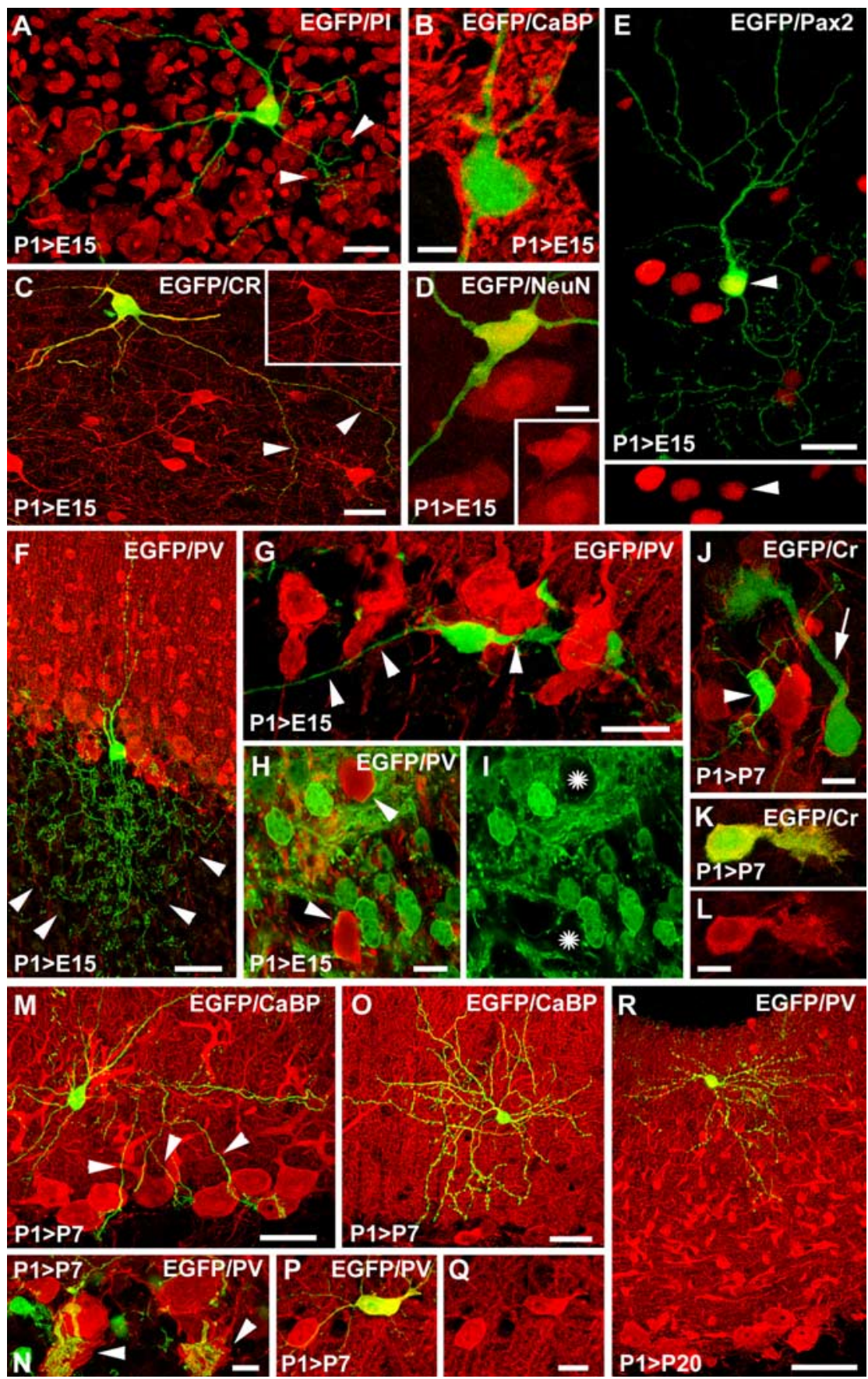

EGFPIPV

Figure 5. $\boldsymbol{A}-\boldsymbol{R}, \mathrm{GABAergic}$ interneurons generated by $\mathrm{P} 1$ cortical or periventricular progenitors grafted embryonic $(\boldsymbol{A}-\boldsymbol{I})$ or postnatal cerebella $(\boldsymbol{J}-\boldsymbol{R})$. The micrographs show representative examples of the phenotypes developed by donor cells. Interneurons of the deep nuclei $(\boldsymbol{A}-\boldsymbol{D})$ are characterized by small round-like perikarya $(\boldsymbol{A})$ covered by calbindin-immunolabeled Purkinje axon terminals $(\boldsymbol{B})$, long slender dendrites, and a short axon branching close to the cell body (arrowheads in $\boldsymbol{A}, \boldsymbol{C}$ ). These cells are also labeled by anti-calretinin ( $\boldsymbol{C}$, inset) and anti-NeuN ( $\boldsymbol{D}$, inset) antibodies. Golgi cells $(\boldsymbol{E}, \boldsymbol{F})$ are located at various depth in the granular layer; they display highly branched axonal arbors in the granular layer (arrowheads in $\boldsymbol{F}$ ) and dendrites elongating into the molecular layer. They are also stained by anti-Pax2 antibodies (arrowhead in $\boldsymbol{E}$, inset). $\boldsymbol{G}$ shows an EGFP-positive Lugaro cell, whose dendrites are typically extended along the Purkinje cell layer. $\boldsymbol{H}$ and $\boldsymbol{I}$ show a cluster of donor granule cells that remained ectopically positioned in the deep white matter of the recipient cerebellum. Arrowheads in $\mathbf{H}$ point to two parvalbumin-immunopositive interneurons of host origin (asterisks in I indicate their position, showing that they do not express EGFP) intermingled with the donor cells. The arrow in Jpoints to a unipolar brush cell derived from a P1 donor grafted to a P7 host; arrowhead indicates an EGFP-positive granule neuron. A fraction of the donor unipolar brush cells was also immunostained for calretinin $(\boldsymbol{K}, \boldsymbol{L})$. Mshows a basket cell with several axon branches (arrowheads) impinging on Purkinje cell bodies. The higher-magnification picture $\boldsymbol{N}$ illustrates the correct integration of donor basket axons in the recipient pinceaux (arrowheads) at the basal pole of Purkinje cell perikarya. A typical stellate cell is displayed in $\mathbf{0 . P}$ and $\mathbf{Q}$ show that donor molecular layer interneurons also express parvalbumin. $\boldsymbol{R}$ depicts another stellate cell in the uppermost region of the molecular layer of a P20 host. P1 $>$ E15, P1 donor to E15 host; $\mathrm{P} 1>\mathrm{P} 7, \mathrm{P} 1$ donor to P7 host; P1 $>\mathrm{P} 20, \mathrm{P} 1$ donor to P20 host. $A-C, E, H, I, K-M, P, Q, R$, Cortical donor cells; $D, F, G, J, N, \mathbf{O}$, periventricular donor cells. PI, Propidium iodide; CaBP, calbindin; PV, parvalbumin; $C$, calretinin. Scale bars: $\boldsymbol{A}, \mathbf{C}, \boldsymbol{E}, \mathbf{G}, \mathbf{M}-\mathbf{Q}, 30 \mu \mathrm{m} ; \boldsymbol{B}, \boldsymbol{D}, \boldsymbol{H}-\mathbf{L}, 10 \mu \mathrm{m}$; $\boldsymbol{F}, \boldsymbol{R}, 50 \mu \mathrm{m}$. 

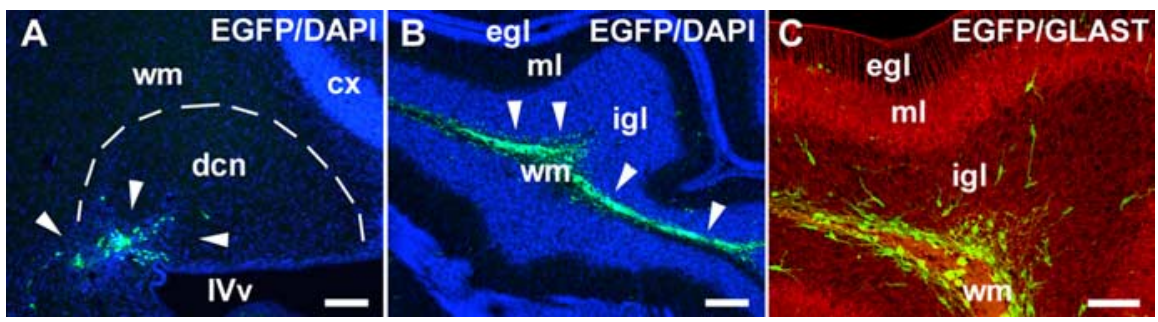

Figure 6. $\boldsymbol{A}-\boldsymbol{C}$, Initial placement of P1 donor cells transplanted to P7 cerebella. The survey micrographs show the position of donor cerebellar cells $1 \mathrm{~d}(\boldsymbol{B}, \boldsymbol{C})$ or $2 \mathrm{~d}(\boldsymbol{A})$ after transplantation. Arrowheads in $\boldsymbol{A}$ point to EGFP-positive cells placed close to the deep cerebellar nuclei (dcn, outlined by the dashed line). When placed in cortical folia $(\boldsymbol{B})$, donor cells (arrowheads) were typically found along the axial white matter, from which they spread into the adjacent cortex. The migration of donor cells (arrowheads in $\boldsymbol{C}$ ) across the cortical layers can be better appreciated in the higher-magnification micrograph $\boldsymbol{C}$, double labeled for EGFP (green) and anti-GLAST antibodies (red). cx, Cerebellar cortex; egl, external granular layer; $\mathrm{ml}$, molecular layer; igl, internal granular layer; wm, white matter; dcn, deep cerebellar nuclei; IVv, fourth ventricle. DAPI, Blue in $\boldsymbol{A}$ and $\boldsymbol{B}$. Scale bars: $\boldsymbol{A}, \boldsymbol{B}, 100 \mu \mathrm{m} ; \boldsymbol{C}, 50 \mu \mathrm{m}$.

which they spread across the granular layer toward the cortical surface (Fig. 6C). In addition, in several cases, the injection track reached deep cerebellar regions, delivering EGFPpositive cells in the central white matter and in the deep nuclei (Fig. 6A) (6 of 18 examined cerebella). Therefore, in these transplants, donor cells were placed in different cerebellar sites, and those injected in the cortex were effectively exposed to the environment of all cortical layers. We then reexamined the animals killed at long term after transplantation. Also in these cases, donor cells were distributed in either the cortex alone or the cortex and the deep cerebellar regions (central white matter and deep nuclei). On this material, we assessed whether the phenotypic distribution of donor-derived interneurons changed according to the graft placement (Table 1). In all instances, considering both cortical or periventricular donors, basket and stellate cells were $>99 \%$ of EGFP-positive interneurons, thus confirming that the interneuron repertoire achieved by transplanted progenitors is not dependent on the graft placement.

Another important factor that may influence the fate choice of transplanted precursors is the composition of the donor cell population. For instance, the presence of substantial amounts of granule cells and their precursors in the cortical cell suspensions could affect the differentiation of interneuron precursors. Although this consideration is somewhat contradicted by the fact that periventricular grafts, which did not contain granule cell, yielded the same patterns of interneuron phenotypes, we asked whether the number of interneurons generated in P1-P7 grafts was related to frequency of other phenotypes derived from donor cells in these grafts (granule neurons and glia) (Carletti et al., 2002). As shown in Table 2, in which the different cases are ordered according to the relative frequency of granule cells, the number of interneurons was not related to that of the other types. To further strengthen the conclusion that the pattern of GABAergic interneurons was not dependent on the composition of the donor cell population, we made an additional series of transplants to P7 cerebella, in which P1 cortical cells were separated from the external granular layer, so to decrease the number of granule neuron progenitors. In these cases, EGFP-positive granule cells were greatly reduced, but the amount of interneurons as well as their phenotypic distribution $(>99 \%$ were molecular layer interneurons) were comparable with those obtained when the whole population of P1 cortical cells was transplanted (Table
2). Therefore, the fate choices of donor cells are not overtly conditioned by the composition of the donor cell population.

\section{Developmental potential of GABAergic interneuron progenitors isolated at different stages of cerebellar ontogenesis}

The experiments described in the previous section show that GABAergic interneuron progenitors residing in cortical or periventricular regions of $\mathrm{P} 1$ cerebella are not limited in their competence for acquiring different mature identities. Nevertheless, it is possible that the potentialities of these precursors are progressively restricted toward late-generated types. To address this question, we examined the fate of cells isolated from the embryonic cerebellar primordium at E14 or dissected from the cerebellar cortex at P7. If a gradual loss of potentiality occurs, then E14 cells should be able to generate the full repertoire of interneurons, whereas those taken at P7 should only be able to adopt the phenotype of molecular layer interneurons.

Embryonic cerebellar cells were grafted to E15 embryos (Fig. $7 A-D$ ) or P7 pups (Fig. $7 E$ ). In line with our previous observations (Carletti et al., 2002), in both hosts, these donors generated Purkinje cells, deep nuclei projection neurons (30 of 55 donorderived nuclear neurons), as well as variable amounts of granule cells. GABAergic interneurons ranged from a few cells to several tens per graft, but the relative frequencies of the various types differed between embryonic or postnatal recipients (Fig. 8D). In the former, there was a majority of deep nuclei and granular layer interneurons, whereas in the latter, molecular layer interneurons predominated (328 of 423 cells, $77.5 \%$ ). Therefore, similar to their P1 counterparts, embryonic donors are competent to generate all interneuron types, which are produced according to the host age and the engraftment site.

To assess the developmental potentialities of late interneuron progenitors, we transplanted P7 cerebellar cells into E15, P1, or P7 hosts. In these cases, we only considered transplants of cortical donor cells because of the extremely poor survival of P7 periventricular donors. The outcome of these experiments was clear-cut. When placed in the embryonic environment, cortical donor cells, isolated at the moment when the bulk of molecular layer interneurons are generated (Altman and Bayer, 1997), produced numerous deep nuclei and granular layer interneurons but rarely adopted basket or stellate cell identities (Figs. $7 F, G, 8 E$ ). In contrast, in $\mathrm{P} 1$ recipients, basket and stellate neurons were the most frequent type, with lower amounts of granular layer or deep nuclei interneurons (Figs. 7H-J, 8E). Finally, when donor cells were homochronically grafted to P7 cerebella, basket and stellate cells were generated almost exclusively (Figs. $7 K, 8 E$ ). Therefore, even such late cortical progenitors retain a full developmental potentiality and are still able to adopt the identity of earlier-generated GABAergic interneurons, according to the neurogenic capabilities of the host cerebellum ontogenetic stage.

\section{Discussion}

To investigate the mechanisms that produce the diversity of cerebellar GABAergic interneurons, we examined the fate of cerebellar progenitors exposed to heterochronic/heterotopic environments. In all conditions, donor cells consistently achieved 
anatomical integration in the recipient cerebellum and acquired interneuron phenotypes appropriate for the host age and engraftment position. These results indicate that the different categories of GABAergic interneurons derive from a common pool of precursors: regardless of their age or location, such cells are able to generate the full repertoire of inhibitory interneurons, and their final identity is determined by site/stage-dependent cues. Therefore, the spatiotemporal sequence of cerebellar interneuron generation is not regulated through a progressive restriction of the potentialities of the progenitor but rather through an instructive mechanism acting on multipotent cells.

\section{Specification of transplanted}

GABAergic interneuron progenitors

Studies on cerebellar patterning and neurogenesis indicate that cell fate choices are primarily determined at the beginning of cerebellar morphogenesis (Herrup and Kuemerle, 1997; Schilling, 2000; Wang and Zoghbi, 2001; Sotelo, 2004). Major neurotransmitter phenotypes derive from progenitor cells that are spatially segregated and molecularly tagged from early developmental stages (Hoshino et al., 2005; Wang et al., 2005; Fink et al., 2006). In addition, there is evidence that specific lineages, including granule cells (Alder et al., 1996) and the same GABAergic interneurons (Maricich and Herrup, 1999), derive from discrete pools of precursors, characterized by distinctive molecular markers and precise positions in the germinal layers. In apparent contrast with this view, lineage analyses indicate that different cerebellar phenotypes, and notably those of inhibitory interneurons (Mathis et al., 1997; Mathis and Nicolas, 2003), may be clonally related and sequentially generated from common progenitors. Transplantation experiments show that certain neuron types are produced by faterestricted cells (Gao and Hatten, 1994; Alder et al., 1996), and late-proliferating progenitors gradually lose the competence for adopting earlier-generated identities (Jankovski et al., 1996; Carletti et al., 2002). Accordingly, in these studies, the fate choices of transplanted cerebellar cells are often scarcely influenced by the recipient environment but primarily predetermined by their original donor site and ontogenetic stage. This picture is not consistent with the present observations, in which donor-derived inhibitory interneurons show strict host-specific phenotypes and incorporation.

In principle, site-specific engraftment and differentiation of donor cells may result from selective mechanisms that favor the survival and integration of defined subsets of committed neuroblasts or fate-restricted precursors. Such mechanisms can hardly
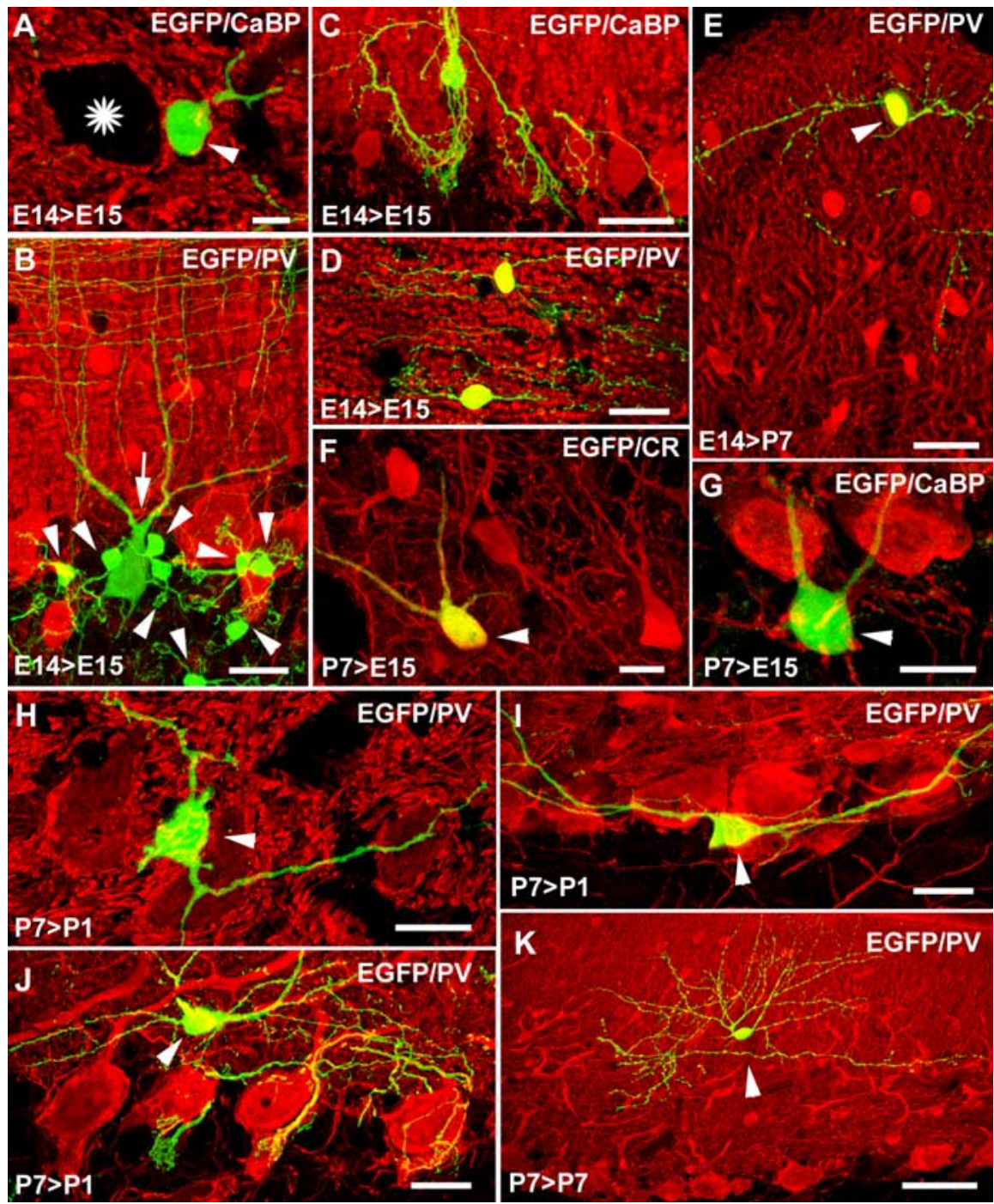

EGFP/PV

Figure 7. $\boldsymbol{A}-\boldsymbol{K}, \mathrm{GABAergic}$ interneurons generated by $\mathrm{E} 14(\boldsymbol{A}-\boldsymbol{E})$ or P7 $(\boldsymbol{F}, \boldsymbol{G})$ donor progenitors. Embryonic cerebellar cells grafted to embryonic recipients $(\boldsymbol{A}-\boldsymbol{D})$ generated all types of interneurons, including deep nuclei interneurons (arrowhead in $\boldsymbol{A}$; asterisk points to a presumptive host projection neuron highlighted by Purkinje axon terminals), Golgi (arrow in $\boldsymbol{B}$; arrowheads indicate granule cells), basket $(\boldsymbol{C})$, and stellate $(\boldsymbol{D})$ cells. When transplanted to P7 hosts $(\boldsymbol{E})$, the same donors produced a vast majority of molecular layer interneurons (arrowhead indicates a parvalbumin-immunopositive stellate cell). $\boldsymbol{F}$ and $\boldsymbol{D}$ show that cerebellar cells isolated at P7 and transplanted to E15 recipients are still able to adopt early-generated identities, such as calretinin-immunopositive interneurons in the deep nuclei (arrowhead in $\boldsymbol{F}$ ) or Golgi cells (arrowhead in $\boldsymbol{G}$ ). The same cells transplanted to P1 hosts $(\boldsymbol{H} \boldsymbol{J})$ still generate interneurons in the deep nuclei (arrowhead in $\boldsymbol{H}$ ), granular layer (arrowhead in $\boldsymbol{I}$ points to a Lugaro cell), and molecular layer (arrowhead in $\boldsymbol{J}$ indicates a basket cell). In contrast, when homochronically transplanted to P7 cerebella $(\boldsymbol{K}), \mathrm{P7}$ progenitors almost exclusively acquire the phenotypes of molecular layer interneurons (arrowhead points to a stellate cell).E14 $>$ E15, E14 donor to E15 host;E14 $>$ P7, E14 donor to P7 host; P7 $>$ E15, P7 donor to E15 host; P7 $>$ P1, P7 donor to P1 host; P7 >P7, P7 donor to P7 host. CaBP, Calbindin; PV, parvalbumin; CR, calretinin. Scale bars: $A, F, 10 \mu \mathrm{m} ; \boldsymbol{B}, \boldsymbol{D}$, E, $30 \mu \mathrm{m} ; \boldsymbol{C}, \boldsymbol{K}, 50 \mu \mathrm{m} ; \boldsymbol{G}-J, 20 \mu \mathrm{m}$.

explain the constant acquisition of host-specific features by cells exposed to heterotopic/heterochronic conditions. (1) To produce this result, a selective mechanism requires that the same repertoire of fate-restricted cells is contained in all donor cell populations. This implies that specified cells destined to become deep nuclei interneurons should still be present in the cerebellar cortex at P7, after the completion of nuclear neurogenesis. (2) In line with the view that committed precursors of deep nuclei interneurons do not reside in the postnatal cortex, retroviruses injected in the cortical white matter at P4 exclusively labeled molecular layer or Golgi interneurons (Zhang and Goldman, 

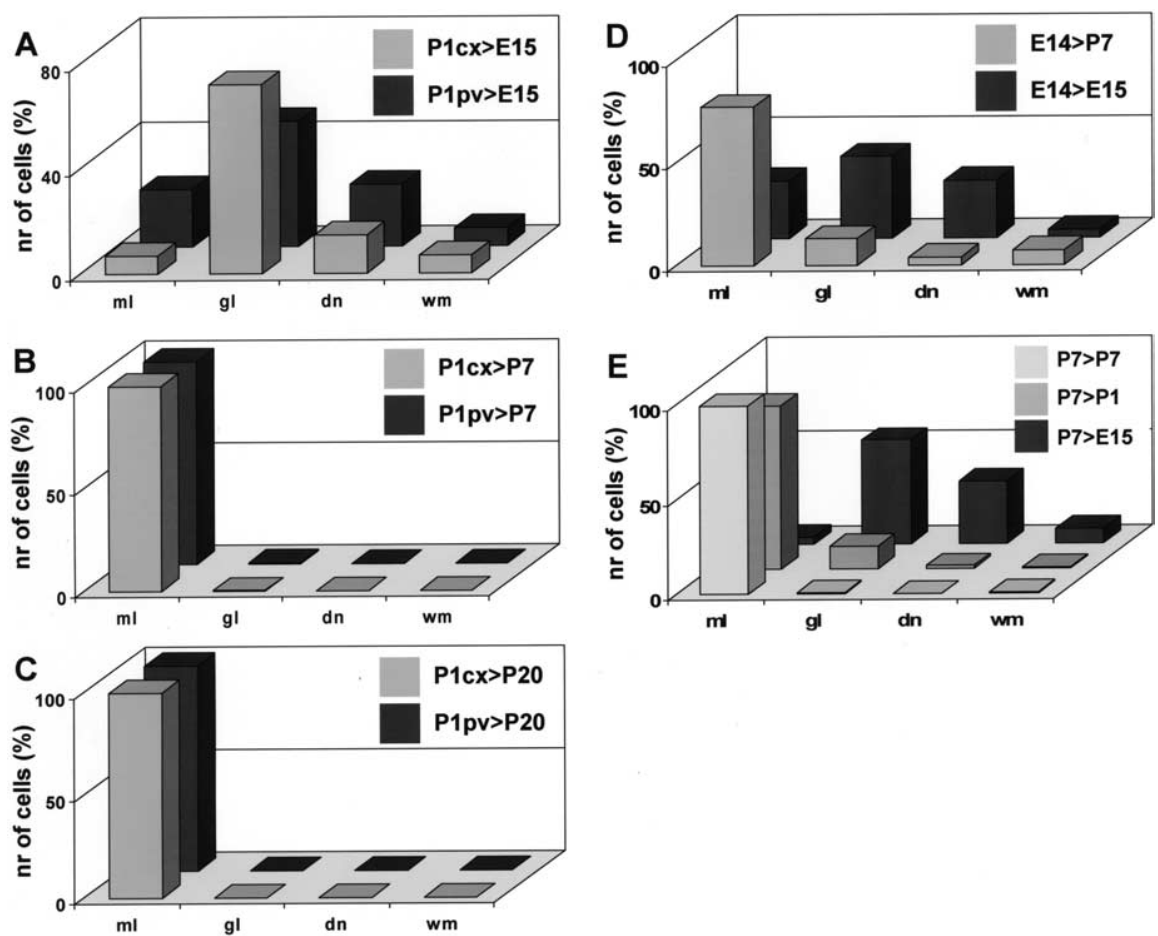

Figure 8. Relative frequencies of the different GABAergic interneuron phenotypes generated by donor cells in the different transplantation experiments. Histograms $A-C$ show the phenotypic repertoires produced by $P 1$ cortical ( $P 1 c x$, light gray bars) or periventricular (P1pv, dark gray bars) cells grafted to E15 (A), P7 (B), or P20 (C) cerebella. $\boldsymbol{D}$ illustrates the distribution of interneuron types produced by E14 donors grafted to P7 (light gray bars) or E15 (dark gray bars) hosts. E reports the distribution obtained with P7 cortical donors transplanted to E15 recipients in utero or to postnatal cerebella at P1 or P7. ml, Molecular layer interneurons (basket and stellate cells); gl, granular layer interneurons (Golgi and Lugaro cells); dn, deep nuclei interneurons; wm, ectopic interneurons in white matter. In all graphs, the frequency of the different phenotypes is represented as percentage of the total number of interneurons observed in all of the cases belonging to the same experimental group (see Fig. 1).

1996a). (3) Mathis and Nicolas (2003) described mixed clones of granular and molecular layer interneurons, which is not consistent with separate lineages. (4) Although donor cells were placed in different cerebellar sites, the repertoire of donor-derived interneurons was always related to the ongoing neurogenic processes in the host. For instance, in P7 recipients, donor cells were exposed to all cortical layers (Fig. 6C) but almost exclusively generated molecular layer interneurons. However, selective mechanisms favoring the survival of specific donor subsets should be also effective beyond the relevant neurogenic period (Carletti and Rossi, 2005). Therefore, our results indicate that the diversity of GABAergic interneurons originates from a common pool of multipotent precursors, which are distributed throughout the whole cerebellum, maintain unaltered potentialities up to the end of development, and adopt mature identities in response to local cues.

The nature of such signals remains to be determined, but in vitro analysis points to multiple effectors, ranging from chemical messengers to electrical activity (Rico et al., 2002; Koscheck et al., 2003). The presence of parvalbumin-immunopositive cells close to ectopic clusters of donor granule neurons (Fig. $5 \mathrm{H}, \mathrm{I}$ ) suggests that critical information may be issued by nearby partners, destined to establish type-specific anatomo-functional interactions with the interneurons. Indeed, the phenotypic repertoires observed in the different transplantation paradigms indicate that host-derived cues are both spatially patterned and time restricted, according to the insideout schedule of interneuron generation. In addition, although the inherent variability of transplantation experiments limits the reli- ability of quantitative estimations, there are some consistent differences in the numbers of engrafted interneurons, which suggest that local cues also control the proliferation rate of transplanted progenitors. For instance, $\mathrm{P} 1$ donors yield $\sim 10$ times more interneurons in $\mathrm{P} 7$ than in $\mathrm{E} 15$ or $\mathrm{P} 20$ hosts (Fig. 1). P7 is at the peak of neurogenesis of basket/stellate cells (Altman and Bayer, 1997; Yamanaka et al., 2004), which are the most abundant category of inhibitory interneurons $[\sim 10$-fold more numerous than Golgi cells (Korbo et al., 1993; Weisheit et al., 2006)]. Therefore, transplanted cells become fully integrated in the host neurogenic mechanisms, which regulate their specification, mitotic pace, and differentiation.

\section{Potentiality of the cerebellar GABAergic interneuron progenitors}

In line with our previous observations (Carletti et al., 2002), embryonic cells developed the full range of cerebellar phenotypes, whereas their postnatal counterparts were restricted to late-generated identities. However, in addition to GABAergic interneurons, the latter donors also produced glutamatergic neurons (granule and unipolar brush cells) and glia, raising the possibility that these types may have related origins.

GABAergic and glutamatergic lineages are strictly separated from early stages of cerebellar morphogenesis (Hoshino et al., 2005; Wang et al., 2005; Fink et al., 2006), and it is established that granule cells and inhibitory interneurons have different origins (Hallonet et al., 1990; Gao and Hatten, 1994; Alder et al., 1996; Zhang and Goldman, 1996,a,b; Mathis et al., 1997). Nevertheless, the boundary between these two lineages may be crossed after different manipulations, including oncogene-induced immortalization (Snyder et al., 1992; Gao and Hatten, 1994) or expansion in vitro (Klein et al., 2005; Lee et al., 2005). Our transplants of freshly dissociated cells are consistent with an exclusive origin of granule cells from the external granular layer, because these neurons were absent when periventricular donors were used. Concerning unipolar brush cells, recent findings about their rhombic lip derivation (Englund et al., 2006), birthdates (Sekerková et al., 2004b), and migratory pathways (Ilijic et al., 2005) suggest that precursors committed to this phenotype are distributed throughout the P1 cerebellar parenchyma and thus contained in both periventricular and cortical donor cell suspensions. Therefore, although the origin of donor-derived unipolar brush cells cannot be definitely established, our observations support the conclusion that transplanted GABAergic and glutamatergic neurons do not share common progenitors.

The possibility that GABAergic interneurons and glia have lineage relationships is also unlikely. Although stem cells that reside in the postnatal cerebellum may be able to generate both types (Klein et al., 2005; Lee et al., 2005), targeted analysis of postnatally proliferating progenitors in situ (Milosevic and Goldman, 2002) or in vitro (Milosevic and Goldman, 2004) indicates that mixed neuronal-glial clones are extremely rare. Because of the low frequency of stem cells in the postnatal cerebellum (Lee et 
al., 2005), they probably contributed marginally to our transplants. Therefore, it is likely that most GABAergic interneurons and glia derived from distinct progenitor sets.

Our results indicate that GABAergic interneurons are generated according to a different strategy from other cerebellar neurons, which derive from fate-restricted precursors (Fig. 9). At the onset of cerebellar morphogenesis, cells in the ventricular zone or rhombic lip are specified to GABAergic and glutamatergic lineages, respectively. Within these germinal layers, subsets of progenitor cells are soon committed to specific fates: deep nuclei projection neurons, granule cells, unipolar brush cells in the rhombic lip, and Purkinje cells in the ventricular zone. Nucleo-olivary neurons, which are born at the same time, likely derive from the latter neuroepithelium, given their neurotransmitter phenotype and the origin of other components of the olivocerebellar system (Wang et al., 2005).

Presumptive progenitors for GABAergic interneurons appear in the ventricular zone at approximately the same stage and soon emigrate into the cerebellar parenchyma, in which they continue to divide and/or differentiate (Zhang and Goldman, 1996a; Maricich and Herrup, 1999). These precursors are clonally related to Purkinje cells (Mathis et al., 1997; Mathis and Nicolas, 2003) but are unable to adopt this or other early-generated identities (Jankovski et al., 1996; Carletti et al., 2002; this study). Conversely, they can develop GABAergic interneuron types that are normally produced at different sites or ontogenetic stages (Baader et al., 1999; this study). Therefore, contrary to all other cerebellar neurons, GABAergic interneurons derive from a pool of precursors generically committed to this type, but competent to develop specific phenotypic traits in response to spatiotemporally patterned instructive signals. Given the relevance of inhibitory mechanisms in the construction and shaping of neural circuits (Levitt et al., 2004; Hensch, 2005), such a strategy offers obvious advantages, because it allows to match types and numbers of interneurons to specific functional requirements of the developing cerebellar network.

\section{References}

Alder J, Cho NK, Hatten ME (1996) Embryonic precursor cells from the rhombic lip are specified to a cerebellar granule neuron identity. Neuron 17:389-399.

Altman J, Bayer SA (1978) Prenatal development of the cerebellar system in the rat. I. Cytogenesis and histogenesis of the deep nuclei and the cortex of the cerebellum. J Comp Neurol 179:23-48. cerebellar development.

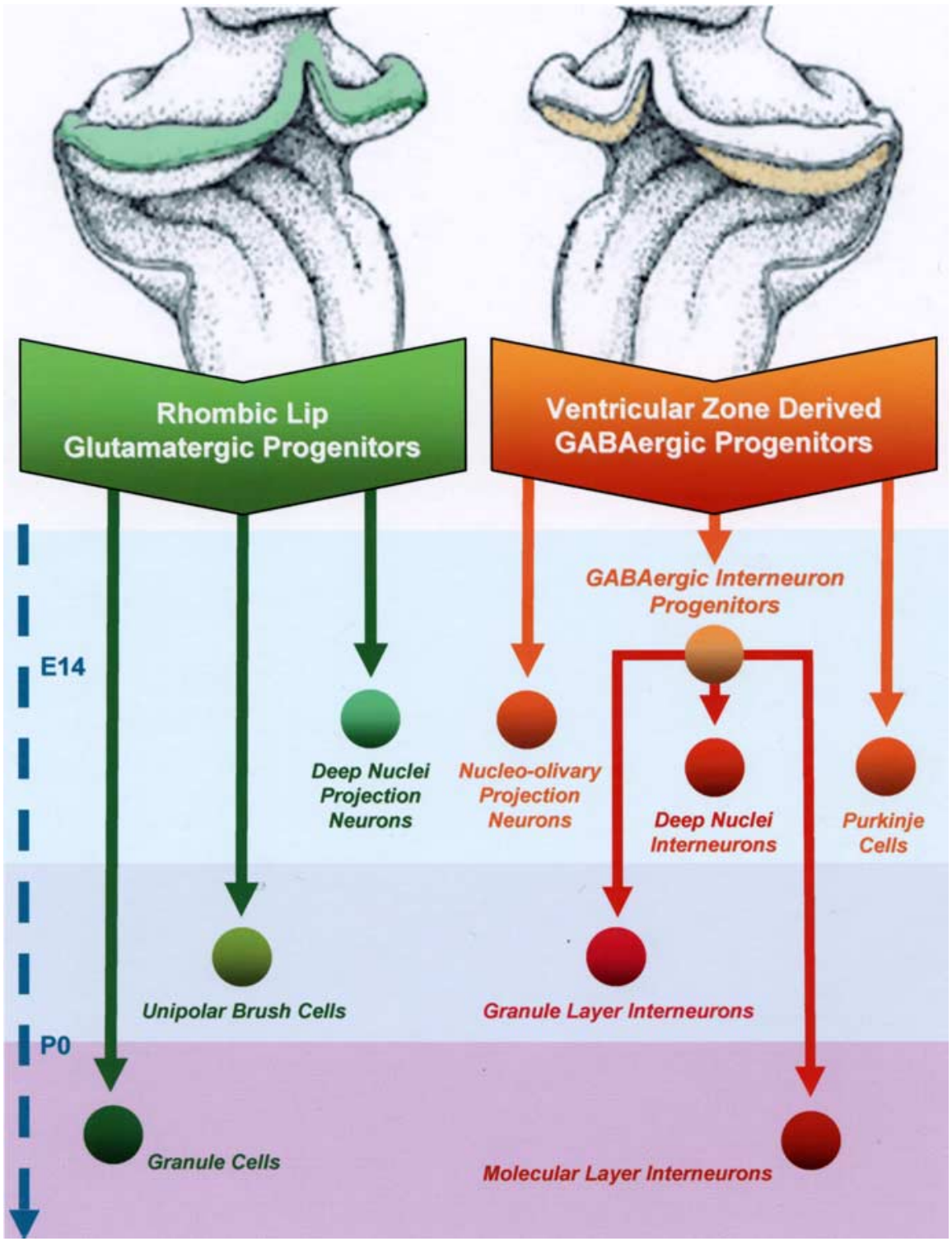

Figure 9. The origins of GABAergic and glutamatergic neurons in the cerebellum. The dumbbell-shaped rhombic lip of the cerebellar anlage (highlighted in green) is the birthplace for progenitors that generate all cerebellar glutamatergic neurons (green arrows). The cerebellar ventricular zone (highlighted in orange) is the birthplace for progenitors that generate all cerebellar GABAergic neurons. These progenitors differentiate into Purkinje cells and likely nucleo-olivary projection neurons (orange arrows). In addition, a subpopulation of progenitors is formed, termed GABAergic interneuron progenitors, that exclusively produces all the GABAergic cerebellar interneurons (red arrows), including deep nuclei interneurons and Golgi and Lugaro cells (granular layer interneurons), as well as basket and stellate cells (molecular layer interneurons), according to the precise spatiotemporal schedule of the developing cerebellum. The timeline on the left of the figure (dashed arrow) depicts the course of

Altman J, Bayer SA (1997) Development of the cerebellar system in relation to its evolution, structures and functions. New York: CRC.

Baader S, Bergmann M, Mertz K, Fox PA, Gerdes J, Oberdick J, Schilling K (1999) The differentiation of cerebellar interneurons is independent of their mitotic history. Neuroscience 90:1243-1254.

Barbe MF, Levitt P (1991) The early commitment of fetal neurons to the limbic cortex. J Neurosci 11:519-533.

Bastianelli E (2003) Distribution of calcium-binding proteins in the cerebellum. Cerebellum 2:242-262.

Batini C, Compoint C, Buisseret-Delmas C, Daniel H, Guegan M (1992) Cerebellar nuclei and the nucleocortical projections in the rat: retrograde tracing coupled to GABA and glutamate immunohistochemistry. J Comp Neurol 315:74-84. 
Carletti B, Rossi F (2005) Selective rather than inductive mechanisms favour specific replacement of Purkinje cells by embryonic cerebellar cells transplanted to the cerebellum of adult Purkinje cell degeneration ( $p c d) \mathrm{mu}-$ tant mice. Eur J Neurosci 22:1001-1012.

Carletti B, Grimaldi P, Magrassi L, Rossi F (2002) Specification of cerebellar progenitors following heterotopic/heterochronic transplantation to the embryonic CNS in vivo and in vitro. J Neurosci 22:7132-7146.

Carletti B, Grimaldi P, Magrassi L, Rossi F (2004) Engraftment and differentiation of neocortical progenitor cells transplanted to the embryonic brain in utero. J Neurocytol 33:309-319.

Cattaneo E, Magrassi L, Butti G, Santi L, Giavazzi A, Pezzotta S (1994) A short term analysis of the behaviour of conditionally immortalized neuronal progenitors and primary neuroepithelial cells implanted into the fetal rat brain. Brain Res Dev Brain Res 83:197-208.

Celio MR (1990) Calbindin D-28k and parvalbumin in the rat nervous system. Neuroscience 32:375-475.

Chan-Palay V (1977) Cerebellar dentate nucleus. Organization, cytology and transmitters. Berlin: Springer.

Desai AR, McConnell SK (2000) Progressive restriction in fate potential by neural progenitors during cerebral cortical development. Development 127:2863-2872.

De Zeeuw CI, Berrebi AS (1995) Postsynaptic targets of Purkinje cell terminals in the cerebellar and vestibular nuclei of the rat. Eur J Neurosci 7:2322-2331

Dino MR, Willard FH, Mugnaini E (1999) Distribution of unipolar brush cells and other calretinin immunoreactive components in the mammalian cerebellar cortex. J Neurocytol 28:99-123.

Englund CM, Kowalczyk T, Daza RAM, Dagan A, Lau C, Rose MF, Hevner RF (2006) Unipolar brush cells of the cerebellum are produced in the rhombic lip and migrate through developing white matter. J Neurosci 26:9184-9195.

Fink AJ, Englund C, Daza RAM, Pham D, Lau C, Nivison M, Kowalczyk T, Hevner RF (2006) Development of the deep cerebellar nuclei: transcription factors and cell migration from the rhombic lip. J Neurosci 26:3066-3076.

Gao WQ, Hatten ME (1994) Immortalizing oncogenes subvert the establishment of granule cell identity in developing cerebellum. Development 120:1059-1070

Grimaldi P, Rossi F (2006) Lack of neurogenesis in the adult rat cerebellum after Purkinje cell degeneration and growth factor infusion. Eur J Neurosci 23:2657-2668.

Grimaldi P, Carletti B, Magrassi L, Rossi F (2005) Fate restriction and developmental potential of cerebellar progenitors. Transplantation studies in the developing CNS. Prog Brain Res 148:57-68.

Hallonet ME, Teillet MA, Le Douarin NM (1990) A new approach to the development of the cerebellum provided by the quail-chick marker system. Development 108:19-31.

Hensch T (2005) Critical period plasticity in local cortical circuits. Nat Rev Neurosci 6:877-888.

Herrup K, Kuemerle B (1997) The compartmentalization of the cerebellum. Annu Rev Neurosci 20:61-90.

Hoshino M, Nakamura S, Mori K, Kawauchi T, Terao M, Nishimura YV, Fukuda A, Fuse T, Matsuo N, Sone M, Watanabe M, Bito H, Terashima T, Wright CVE, Kawaguchi Y, Nakao K, Nabeshima YI (2005) Ptfla, a bHLH transcriptional gene, defines GABAergic neuronal fates in cerebellum. Neuron 47:201-213.

Ilijic E, Guidotti A, Mugnaini E (2005) Malpositioned cerebellar unipolar brush cells in reeler mouse. Neuroscience 136:633-647.

Ito T, Suzuki A, Imai E, Okabe M, Hori M (2001) Bone marrow is a reservoir of repopulating mesangial cells during glomerular remodelling. J Am Soc Nephrol 12:2625-2635.

Jankovski A, Rossi F, Sotelo C (1996) Neuronal precursors in the postnatal mouse cerebellum are fully committed cells: evidence from heterochronic transplantation. Eur J Neurosci 8:2308-2320.

Kioussi C, Gruss P (1994) Differential induction of Pax genes by NGF and BDNF in cerebellar primary cultures. J Cell Biol 125:417-425.

Klein C, Butt SJB, Machold RP, Johnson JE, Fishell G (2005) Cerebellumand forebrain-derived stem cells possess intrinsic regional character. Development 132:4497-4508.

Korbo L, Andersen BB, Ladefoged O, Møller A (1993) Total numbers of various cell types in rat cerebellar cortex estimated using an unbiased stereological method. Brain Res 609:262-268.
Koscheck T, Weyer A, Schilling RL, Schilling K (2003) Morphologica development and neurochemical differentiation of cerebellar inhibitory interneurons in microexplant cultures. Neuroscience 116:973-984.

Lee A, Kessler JD, Read TA, Kaiser C, Corbeil D, Huttner WB, Johnson JE Wechsler-Reya RJ (2005) Isolation of neural stem cells from the postnatal cerebellum. Nat Neurosci 6:723-729.

Levitt P, Livesey KL, Powell EM (2004) Regulation of neocortical interneuron development and the implications for neurodevelopmental disorders. Trends Neurosci 27:400-406.

Livesey FJ, Cepko CL (2001) Vertebrate neural cell-fate determination: lessons from the retina. Nat Rev Neurosci 2:109-118.

Machold R, Fishell G (2005) Mathl is expressed in temporally discrete pools of cerebellar rhombic-lip neural progenitors. Neuron 48:17-24.

Maricich SM, Herrup K (1999) Pax-2 expression defines a subset of GABAergic interneurons and their precursors in the developing murine cerebellum. J Neurobiol 41:281-294.

Mathis L, Nicolas JF (2003) Progressive restriction of cell fates in relation to neuroepithelial cell mingling in the mouse cerebellum. Dev Biol 258:20-31.

Mathis L, Bonnerot C, Puelles L, Nicolas JF (1997) Retrospective clonal analysis of the cerebellum using genetic laacZ/lacZ mouse mosaics. Development 124:4089-4104.

McConnell SK, Kaznowski CE (1991) Cell cycle dependence of laminar determination in developing neocortex. Science 254:282-285.

Miale IL, Sidman RL (1961) An autoradiographic analysis of histogenesis in mouse cerebellum. Exp Neurol 4:277-296.

Milosevic A, Goldman JE (2002) Progenitors in the postnatal cerebellar white matter are antigenically heterogeneous. J Comp Neurol 452:192-203.

Milosevic A, Goldman JE (2004) Potential of progenitors from postnatal cerebellar neuroepithelium and white matter: lineage specified vs multipotent fate. Mol Cell Neurosci 26:342-353.

Mullen RJ, Buck CR, Smith AM (1992) NeuN, a specific neuronal nuclear protein in vertebrates. Development 116:201-211.

Nelson BJ, Mugnaini E (1989) Origin of GABAergic inputs to the inferior olive. In: The olivocerebellar system in motor control, Experimental brain research series 17 (Strata P, ed), pp 86-107. Berlin: Springer.

Okabe M, Ikawa M, Kominami K, Nakanishi T, Nishimune Y (1997) "Green mice" as a source of ubiquitous green cells. FEBS Lett 407:313-319.

Palay SL, Chan-Palay V (1974) Cerebellar cortex. Cytology and organization. Berlin: Springer.

Pearson BJ, Doe CQ (2004) Specification of temporal identity in the developing nervous system. Annu Rev Cell Dev Biol 20:619-647.

Ramón y Cajal S (1911) Histologie du système nerveux de l'homme et des vertébrés. Paris: Maloine.

Rico B, Xu B, Reichardt LF (2002) TrkB receptor signaling is required for establishment of GABAergic synapses in the cerebellum. Nat Neurosci 5:225-233.

Rossi F, Wiklund L, van der Want JJL, Strata P (1991) Reinnervation of cerebellar Purkinje cells by climbing fibres surviving a subtotal lesion of the inferior olive. I. Development of new collateral branches and terminal plexuses. J Comp Neurol 308:513-535.

Ruigrok TJH (1997) Cerebellar nuclei: the olivary connection. Prog Brain Res 114:167-192.

Schilling K (2000) Lineage, development and morphogenesis of cerebellar interneurons. Prog Brain Res 124:51-68.

Sekerková G, Ilijic E, Mugnaini E (2004a) Bromodeoxyuridine administered during neurogenesis of the projection neurons causes cerebellar defects in rat. J Comp Neurol 470:221-239.

Sekerková G, Ilijic E, Mugnaini E (2004b) Time of origin of unipolar brush cells in the rat cerebellum as observed by prenatal bromodeoxyuridine labeling. Neuroscience 127:845-858.

Snyder EY, Deitcher DL, Walsh C, Arnold-Aldea S, Hartweig EA, Cepko CL (1992) Multipotent neural cell lines can engraft and participate in development of mouse cerebellum. Cell 68:33-51.

Sotelo C (2004) Cellular and genetic regulation of the development of the cerebellar system. Prog Neurobiol 72:295-339.

Sultan F, Czubayko U, Thier P (2003) Morphological classification of the rat 
lateral cerebellar nuclear neurons by principal component analysis. J Comp Neurol 455:139-155.

Wang VY, Zoghbi HY (2001) Genetic regulation of cerebellar development. Nat Rev Neurosci 2:484-491.

Wang VY, Rose MF, Zoghbi H (2005) Math1 expression redefines the rhombic lip derivatives and reveals novel lineages within the brainstem and cerebellum. Neuron 48:31-43.

Weisheit G, Gliem M, Endl E, Pfeffer PL, Busslinger M, Schilling K (2006) Postnatal development of the murine cerebellar cortex: formation and early dispersal of basket, stellate and Golgi neurons. Eur J Neurosci 24:466-478.

Weyer A, Schilling K (2003) Developmental and cell type-specific expres- sion of the neuronal marker NeuN in the murine cerebellum. J Neurosci Res 73:400-409.

Wingate RJT (2001) The rhombic lip and early cerebellar development. Curr Opin Neurobiol 11:82-88.

Yamanaka H, Yanagawa Y, Obata K (2004) Development of stellate and basket cells and their apoptosis in mouse cerebellar cortex. Neurosci Res 50:13-22.

Zhang L, Goldman JE (1996a) Generation of cerebellar interneurons from dividing progenitors in white matter. Neuron 16:47-54.

Zhang L, Goldman JE (1996b) Developmental fates and migratory pathways of dividing progenitors in the postnatal rat Cerebellum. J Comp Neurol 370:536-550. 